\section{Trends in the management of prolactinomas}

The management of patients with pituitary tumours has undergone a reappraisal with recent developments in our understanding of the neuroendocrine control of pituitary hormone secretion. The radioimmunoassay for prolactin ${ }^{1}$ has led to the recognition of a further subgroup of secretory pituitary tumours, the prolactinomas, which have proved to be the most frequent type of secretory pituitary tumour. ${ }^{2}$ Now that radioimmunoassays and improved neuroradiological techniques permit earlier detection of tumours, often before any changes in the size of the sella, the emphasis has swung to early selective treatment of these microadenomas with preservation of surrounding normal pituitary tissue.

The conventional pattern of investigation of patients with suspected pituitary tumours has been to establish that hormone secretion is excessive and to determine the anatomical extent of the tumour mass and its effect on surrounding normal pituitary tissue. Increasing awareness of the various clinical presentations of these tumours should lead to earlier referral of patients with more localised, less destructive lesions.

Women with prolactinomas characteristically present with menstrual dysfunction and infertility with or without galactorrhoea, associated with sustained non-stress-induced hyperprolactinaemia-though the many other causes of a raised serum concentration of prolactin still need to be excluded. $^{34}$ In contrast, men with prolactinomas tend to present late with loss of libido, impotence, and symptoms and signs resulting from a space-occupying lesion of the pituitary, commonly when the tumour has already expanded out of the fossa. ${ }^{5}$

The merits of the various methods of investigation of tumour size are a subject of current controversy. Plain lateral and posterior-anterior radiographs of the skull may show gross abnormalities, but whether these methods can detect minor degrees of asymmetry (even in conjunction with computed tomography) has been disputed, ${ }^{6} 7$ despite subsequent surgical confirmation of the lesions responsible. Clearly a report of a completely normal fossa on radiological examination does not exclude the presence of a microadenoma. The size of the fossa is an inaccurate measure of the extent of a tumour, since degrees of "empty fossa" can occur, with or without evidence of previous pituitary infarction. ${ }^{8}$ Carotid arteriography is a wise precaution before operation ${ }^{9}$ since it defines the location of the carotid artery and excludes the possibility that the cause of the abnormal fossa is an aneurysm. The extent of the tumour was usually assessed by air encephalography before the introduction of computed tomography. The latter, however (with or without intravenous iodinated and intrathecal metrizamide contrast media), is easier to perform and associated with fewer and less severe side effects than is air encephalography. ${ }^{10-12}$ Furthermore, computed tomography is more easily repeated in patients who need monitoring of the changes in tumour size in response to treatment. ${ }^{13}$

Two major developments have occurred in the treatment of prolactinomas: refinement of surgical techniques and the introduction of bromocriptine. Interest has been renewed in the transsphenoidal surgical approach to the pituitary, and with increasing expertise this technique (as facilitated by fluoroscopic image intensification and the operating microscope) has evolved from complete hypophysectomy to selective microadenomectomy. ${ }^{14}$ The transfrontal approach is now used when vision is threatened by an upwardly extending lesion. Bromocriptine may provide an alternative to surgery in some cases. This ergot derivative ${ }^{15}$ with long-acting dopamine-agonist properties ${ }^{\mathbf{1 6}}$ is a potent inhibitor of prolactin secretion ${ }^{17}$; and clinical studies, particularly by Besser and his colleagues, have established that it has a place in the definitive treatment of hyperprolactinaemia. ${ }^{18}$

At present the treatment for prolactinomas depends to a substantial extent on the expertise available in the various centres-and on the size of the tumour. Results from Hardy and his colleagues in Montreal, ${ }^{14}$ confirmed by others, ${ }^{19} 20$ have shown the high "cure" rates that are attainable by selective removal of microadenomas by the transsphenoidal approach. These success rates fall with increasing tumour size and prolactin concentrations. ${ }^{20}$ Data on long-term follow-up are not yet available for patients treated in this way; but in the meantime-and provided that the surgical skill is available-this seems the treatment of choice for small tumours. In centres where selective microadenomectomy cannot be performed and for patients with larger tumours the choice lies between complete hypophysectomy via the transsphenoidal route and treatment with bromocriptine. The radical approach seems difficult to justify in young women seeking pregnancy when bromocriptine has proved so successful in restoring menstruation and fertility. Definite evidence has been reported of reduction in the size of prolactinomas in response to treatment with bromocriptine, ${ }^{13}$ confirming earlier animal work, ${ }^{21}$ and medical treatment has now established its place. Bromocriptine may reasonably be given to patients with prolactinomas irrespective of size, though special care is needed in patients with visual impairment and those with a recurrence of tumours after previous surgery or irradiation. Reduction of larger tumours into the fossa might make "cure" possible by subsequent transsphenoidal surgery.

Though there is no evidence that bromocriptine is associated with an increased incidence of multiple births, fetal abnormalities, or increased abortion rates, ${ }^{22}$ patients are still advised to discontinue the drug as soon as they become pregnant. Since infertile women with prolactinomas wishing to conceive do so readily and fairly rapidly after starting treatment with bromocriptine there is a real risk that the tumour will expand again during pregnancy, and external pituitary irradiation has been advocated before such women attempt to conceive. ${ }^{23}$ Stopping treatment after short periods had been thought to be associated with renewed hyperprolactinaemia, but a recent report by Eversmann and his colleagues ${ }^{24}$ suggests that this may not be the case for macroadenomas.

Despite these dramatic improvements in investigation and treatment, detection of pituitary tumours remains the main problem. Advances may result from pharmacological manipulation of the hypothalamic-pituitary regulatory system. Dopamine is the main physiological prolactin-inhibiting factor. ${ }^{25}$ The sustained hyperprolactinaemia observed in patients with prolactinomas is almost certainly due to an alteration in the neurotransmitter regulatory system. ${ }^{26}$ Whether the defect is central, in the hypothalamus, or local, in the pituitary lactotroph cell, remains uncertain. The excellent clinical and biochemical response to selective microadenomectomy and the fact that normal tissue surrounding the microadenoma has a different response from prolactin to testing of the dopamine control system ${ }^{27} 28$ both favour a local and selective defect in the dopaminergic inhibition of prolactin release. The degree of autonomy of the resulting adenoma is probably reflected in the variable responses 
reported in patients with prolactinomas ${ }^{27-32}$ after testing with thyrotrophin-releasing hormone and dopamine antagonists. More reliable information seems likely to come from investigation of the effect on the normal tissue surrounding the adenoma of the increased dopaminergic activity that results from the prolactin feedback on the hypothalamus. Preliminary studies on the gonadotrophin response to metoclopramide ${ }^{27}$ and the thyrotrophin response to domperidone ${ }^{28}$ in patients with prolactinomas provide evidence for this hypothesis. If substantiated, this may lead to earlier reliable detection of microadenomas, with prospects of even better "cure" rates.

${ }^{1}$ Hwang $\mathrm{P}$, Guyda H, Friesen $\mathrm{H}$. A radioimmunoassay for human prolactin. Proc Natl Acad Sci USA 1971;68:1902-6.

2 Antunes JL, Housepian EM, Frantz AG, et al. Prolactin-secreting pituitary tumors. Ann Neurol 1977;2:148-53.

3 Jacobs HS, Franks S, Murray MAF, Hull MGR, Steele SJ, Nabarro JDN. Clinical and endocrine features of hyperprolactinaemic amenorrhoea. Clin Endocrinol (Oxf) 1976;5:439-54.

4 Kleinberg DL, Noel GL, Frantz AG. Galactorrhea: a study of 235 cases including 48 with pituitary tumors. $N$ Engl $\mathcal{F}$ Med 1977;296:589-600.

5 Carter JN, Tyson JE, Tolis G, Van Vliet S, Faiman C, Friesen HG. Prolactin-secreting tumors and hypogonadism in 22 men. $N$ Englf $\mathrm{Med}$ $1978 ; 299: 847-52$.

- Swanson HA, Du Boulay G. Borderline variants of the normal pituitary fossa. $\mathrm{Br} \mathcal{F}$ Radiol $1975 ; 48: 366-9$.

7 Vezina JL. Prolactin-secreting pituitary adenomas: radiologic diagnosis. In: Robyn C, Harter M, eds. Progress in prolactin physiology and pathology. Amsterdam: Elsevier/North Holland Biomedical Press, 1978:351-60.

${ }^{8}$ Hall K, McGregor AM, Scanlon MF, Hall R. A new radiological approach to the assessment of large prolactin-secreting pituitary adenomas treated with bromocriptine. In: Progress in reproductive biology. Basle: Karger (in press).

9 White JC, Ballantine HT. Intrasellar aneurysms simulating hypophyseal tumours. F Neurosurg $1961 ; 18: 34-42$.

10 Drayer B, Kattah J, Rosenbaum A, Kennerdell J, Maroon J. Diagnostic approaches to pituitary adenomas. Neurology (Minneap) 1979;29:161-9.

11 Gross CE, Binet EF, Esguerra JV. Metrizamide cisternography in the evaluation of pituitary adenomas and the empty sella syndrome. f Neurosurg 1979;50:472-6.

12 Hall K, McAllister VL. Metrizamide cisternography in pituitary and juxtapituitary lesions. Radiology 1980;134:101-8.

13 McGregor AM, Scanlon MF, Hall R, Hall K. Effects of bromocriptine on pituitary tumour size. $\mathrm{Br}$ Med $\mathcal{F} 1979$;ii:700-3.

14 Hardy J, Beuregard H, Robert F. Prolactin-secreting pituitary adenomas: transsphenoidal microsurgical treatment. In: Robyn C, Harter M, eds. Progress in prolactin physiology and pathology. Amsterdam: Elsevier/ North Holland Biomedical Press, 1978:361-70.

15 Flückiger E, Doepfner W, Markó M, Niederer W. Effect of ergot alkaloids on the hypothalamic-pituitary axis. Postgrad Med $\mathcal{F} 1976 ; 52$,suppl 1: 57-61.

${ }^{16}$ Corrodi H, Fuxe K, Hokfelt T, Lidbrink P, Ungerstedt U. Effect of ergot drugs on central catecholamine neurones: evidence for a stimulation of central dopamine neurones. F Pharm Pharmacol 1973;25:409-11.

17 Pasteels JL, Danguy A, Frerotte $M$, Ectors F. Inhibition de la sécrétion de prolactine par l'ergocornine et la 2-Br-a-ergocryptine. Ann Endocrinol (Paris) 1971 ;32:188-92.

18 Thorner MO. Prolactin: clinical physiology and the significance and management of hyperprolactinaemia. In: Martini L, Besser GM, eds. Clinical neuroendocrinology. New York: Academic Press, 1977:319-61.

19 Jaquet P, Grisoli F, Guibout M, Lissitzky J-C, Carayon P. Prolactin secreting tumors-endocrine status before and after surgery in 33 women. $\mathcal{F}$ Clin Endocrinol Metab 1978;46:459-66.

${ }^{20}$ Keye WR, Chang RJ, Monroe SE, Wilson CB, Jaffe RB. Prolactinsecreting pituitary adenomas in women. 2. Menstrual function, pituitary reserves and prolactin production following microsurgical removal. Am F Obstet Gynecol 1979;134:360-5.

21 Quardi SK, Lu KH, Meites J. Ergot-induced inhibition of pituitary tumor growth in rats. Science $1972 ; 176: 417-8$.

22 Griffith RW, Turkalj I, Braun P. Outcome of pregnancy in mothers given bromocriptine. Br f Clin Pharmacol 1978;5:227-31.

23 Thorner MO, Edwards CRW, Charlesworth $M$, et al. Pregnancy in patients presenting with hyperprolactinaemia. $B r$ Med F 1979;ii:771-4.

${ }^{24}$ Eversmann T, Fahlbusch R, Kjosk HK, Von Werder K. Persisting suppression of prolactin-secretion after long-term treatment with bromocriptine in patients with prolactinomas. Acta Endocrinol $(\mathrm{Kbh})$ 1979;92:413-27.

${ }^{25}$ Macleod RM, Lehmeyer JE. Studies on the mechanism of the dopaminemediated inhibition of prolactin secretion. Endocrinology 1974;94: 1077-85.

${ }^{26}$ Fine SA, Frohman LA. Loss of central nervous system component of dopaminergic inhibition of prolactin secretion in patients with prolactinsecreting pituitary tumors. F Clin Invest 1978;61:973-80.
27 Quigley ME, Judd SJ, Gilliland GB, Yen SSC. Effects of a dopamine antagonist on the release of gonadotropin and prolactin in normal women and women with hyperprolactinemic anovulation. $\mathcal{F}$ Clin Endocrinol Metab 1979;48:718-20.

${ }^{28}$ Scanlom MF, Rodriguez-Arnao MD, McGregor AM, et al. A new approach to the identification of prolactin-secreting microadenomas? In: Progress in reproductive biology. Basle: Karger (in press).

${ }^{29}$ Muller EE, Genazzani AR, Murru S. Nomifensine: diagnostic test in hyperprolactinemic states. $\mathcal{F}$ Clin Endocrinol Metab 1978;47:1352-7.

${ }^{30}$ Cowden EA, Ratcliffe JG, Thomson JA, Macpherson P, Doyle D. Teasdale GM. Tests of prolactin secretion in diagnosis of prolactinomas. Lancet $1979 ; \mathrm{i}: 1155-8$.

31 Dunne MJ, Walker J, Cowden EA, Ratcliffe JG. Nomifensine test for investigation of hyperprolactinaemia. Lancet 1979 ;ii:1243.

32 Klijn JGM, Lamberts SWJ, Birkenhäger JC. TRH test for prolactinoma. Lancet 1979 ;ii:581-2.

\section{Lungs and legionnaires' disease}

Legionnaires' disease is a pneumonia of variable severity that first achieved clinical notoriety in 1976, when it struck down delegates at the Pennsylvania State American Legion at Philadelphia. ${ }^{1-3}$ Later, serological studies showed that outbreaks of the condition had been occurring in the United States since at least 1965 , on some occasions of considerably milder type than in the Philadelphia outbreak. The organism is a somewhat elusive Gram-negative bacterium which has been named Legionella pneumophila; the histological techniques required to identify it include silver-impregnation methods on paraffin-embedded tissue and special staining methods on tissue imprints and smears of secretions from the respiratory tract. It can be cultured on artificial bacteriological media, in the yolk sac of fertile hens' eggs, and by intraperitoneal inoculation of guinea-pigs. Legionnaires' disease can also be diagnosed retrospectively by finding antibodies against the organism in convalescent serum using an indirect immunofluorescence technique.

In fatal cases the lungs bear the brunt of the disease. The usual picture is an extensive confluent bronchopneumonia, which sometimes spreads so much as to have a lobar distribution. When the pneumonia is lobular and closely associated with the bronchioles, the organism may be presumed to have gained entry to the lungs by inhalation. When, on the other hand, the distribution of the pneumonia is fully lobar, the possibility of blood-borne dissemination should also be considered. In classic pneumococcal lobar pneumonia the rapid spread of infection is taken as evidence of an allergic phenomenon superimposed on the infective element: a whole lobe is rapidly submerged in a gigantic wave of oedematous exudate. This phenomenon has been explained on the relatively symptomless passage of the pneumococci through the lungs after their initial inhalation, their direct passage into the blood stream, their proliferation in the cells of the reticuloendothelial system, and their return to the blood to be carried once more to the lungs as part of a septicaemia. As they return to the now sensitised lungs so they evoke a massive allergic response that implicates an entire lobe.

Hernandez and colleagues ${ }^{4}$ have recently reviewed the necropsy findings in 20 cases of legionnaires' disease. The constant features were limited to the lungs. Usually there was a confluent bronchopneumonia, but sometimes the consolidation had a lobar distribution. In the 17 patients who died in the acute phase the characteristic histological features were an extensive exudation into the alveoli of macrophages and 